\title{
Estimation of the Predictive Powers of Parental Support and Domestic Violence on Child Abuse Among Primary School Pupils in South-East, Nigeria
}

\author{
Emmanuel Chidobe Okenyi ${ }^{1}$, Anthonia N. Ngwoke ${ }^{1}$, Gloria C. Ugwu ${ }^{1}$, Anthonia O. Aneke ${ }^{1}$, Clara O. Ifelunni ${ }^{1}$, \\ Elizabeth N. Ebizie ${ }^{1}$, Joy Chioma Orji ${ }^{2}$, Juliana N. Ejiofor ${ }^{1}$, Obiageli C. Njoku ${ }^{1}$, Victor S. Ezema ${ }^{1}$, \\ Wilfred Iorfa Achagh ${ }^{3}$, Julie. U. Ibiam ${ }^{1} \&$ Christian S. Ugwuanyi ${ }^{4}$ \\ ${ }^{1}$ Department of Educational Foundations, University of Nigeria, Nsukka, Nigeria \\ ${ }^{2}$ Institute of Education, University of Abuja, Nigeria \\ ${ }^{3}$ Department of Early Childhood Care and Education, FCT College of Education Zuba, Abuja, Nigeria \\ ${ }^{4}$ Department of Science Education, University of Nigeria, Nsukka, Nigeria \\ Correspondence: Christian S. Ugwuanyi, Department of Science Education, University of Nigeria, Nsukka, \\ Nigeria. E-mail: christian.ugwuanyi@unn.edu.ng
}

Received: September 18, 2019 Accepted: October 31, 2019 Online Published: November 10, 2019

doi:10.5539/gjhs.v11n14p23

URL: https://doi.org/10.5539/gjhs.v11n14p23

\begin{abstract}
The general purpose of the study was to estimate the predictive powers of parental support and domestic violence on child abuse among pupils in South-East, Nigeria. The study was guided by two research questions and two null hypotheses. The study adopted a correlational survey research design with a population of 481,533 primary five pupils in public primary schools in South-East, Nigeria. A sample of 400 primary five pupils' was drawn using a multi-stage sampling procedure. Three instruments were used for data collection: Parental Social Support Questionnaire (PSSQ), Parental Domestic Violence Questionnaire (PDVQ) and Child Abuse Questionnaire (CAQ). The reliability of the instrument was established by trial-testing on 30 primary five pupils that were not part of the sample. Cronbach's Alpha Reliability method was used to determine the internal consistency of the instruments. The reliability coefficients of $0.88,0.80$ and 0.75 were obtained for parental social support questionnaire, parental domestic violence and child abuse questionnaire. Data collected were analyzed using simple linear regression analysis. Specifically, the Coefficient of Determination $\left(\mathrm{r}^{2}\right)$ was used to answer research questions and Analysis of Variance (ANOVA) aspect of simple linear regression was used to test the hypotheses at 0.05 level of significance. The findings of the study revealed that parental social support significantly predicted child abuse negatively while domestic violence significantly predicted child abuse positively. Based on the findings of the study, it was recommended among others that parents should provide enough social support to their children's proper development and emotional stability.
\end{abstract}

Keywords: parental support, domestic violence, predictor, child abuse

\section{Introduction}

A parent is any person male or female whose gamete resulted in the offspring (Browne, 2012). This is the case in a biological parent. Bedford (2018) defined parent as any person who may through the law of adoption or otherwise exercise parental responsibility for a young person. In the context of this study, a parent is the one who has the legal, social and moral responsibility for a child's growth and development. Parents are the primary caregivers, protectors and educators of young children.

Children need care, security, stability, consistency, emotional support, love among others for adequate growth and development. According to Johanna (2015), children need a stable living environment which is peaceful and safe as well as adequate dieting and other basic needs for proper growth and development. According to ChangingMinds.Org (2018), it is the responsibility of the parents to provide these developmental needs of the child starting from the moment of conception. Among Nigerian parents, the extent to which parents are meeting up with their obligations towards the child's growth and development is indeterminable. The issue of child abuse, therefore, comes in when the parent fails in his or her responsibility towards the child. Personal observation reveals that many 
children in Nigeria seem not to be receiving adequate provisions from their parents. One may say that many Nigerian children appear to be abused in one way or the other.

The term child abuse refers to all activities by adults or organizations that may impact negatively on the child. Child abuse refers to any condition that is injurious to the physical or emotional health of the child that has been inflicted on the child by the parents, guardian or other caregivers (Obekpe, 2011). Similarly, Antai, Braithwaite, and Clerk (2016) viewed child abuse as consisting of any acts of commission or omission by a parent, caregiver or other adult resulting in harm, or potentially harmful, or threat of harm to a child even if the harm is unintended. Child abuse is, therefore, any activity or inactivity of an adult or institution that impact negatively on the well-being of the child. The extent of child abuse by parents may be determined by parental social support and domestic violence.

Parental support refers to the backing, care, maintenance, provision, and funding a child receives from the parents. According to Ajila and Olutola (2001), parental support is the sum total of the commitment given to the child by the parents which could be financial, social, moral, developmental, educational among others. Ruholt, Gore and Dukes (2015), stated that parental support may play a significant role in the development and learning outcomes of the child. Therefore, parental support may be of significant effect on the development and learning outcomes of the child. In this study, parental support was limited to social support provided by parents to the child. Parental Social support encompasses most of the other forms of parental support (Beth, Lisa, Rylin, \& SCoth, 2016).

Social support refers to how the individual perceives oneself within the family, organization or community. Social support is the physical and emotional comfort given to an individual by the family, friends, co-workers, and others. It is the awareness that a person or a child is a part of a community of people who love and care, value and think well of the individual (Fairbrother, 2011). Social support enhances the quality of life and provides a buffer against adverse life events including child abuse (Sue, 2015). Therefore, social support is the care and love a child receives from the parent(s). The perception and awareness that the child is cared for, has assistance available from the parent(s), include having the parent(s) listen and show interest (emotional support), sharing information and offering suggestions (information support), fulfilment with support received and Criticism from the parent(s) (negative social interaction). Social support can be measured from the perspective of either the recipient or the provider or both (Gottlieb \& Bergen, 2009). However, the interest here is on the predictive value of parental social support towards child abuse and academic achievement of pupils in social studies.

Parental social support refers to the quality of family interaction experienced by the child in the home. Social support is the care and nurturing the child receives from the parent(s). Parental social support can be seen as consisting of different forms of support children receive from parents (Heredia, Ranjit, Warren, \& Evans, 2016). Parental social support in this study refers to the love, care and encouragement children receive from parents that enhance the children's development and learning outcomes. A child can only feel secure and utilize the available parental social support in a family devoid of violence. In a family besieged with violence (domestic violence), parents may not provide adequate social support for the children.

Domestic violence is perceived as a form of behaviour intended to intimidate and gain control over a partner, a spouse or a close family member, especially in the household and is a preventable issue of public health. According to Florida Coalition against Domestic Violence (FCADV) (2014), domestic violence is a form of behaviour or threats of violence used by one person to establish power and control over an intimate partner and so control the partner's behaviours. This is to say that crux of the matter in domestic violence is about control and supremacy. therefore, Domestic violence is any action or behaviour of a partner with the intention to intimidate and gain undue control of the spouse or intimate family members such as beating and hitting a spouse before the children, talking down on the spouse before the children and starving the spouse of fund with the knowledge of the children. Children who witness domestic violence may be abused emotionally and are at risk of physical abuse (Fairbrother, 2011). All these factors border around social interaction at high which leads to the development of social skills. If the social skills of the spouses and other members of the family are adequately developed, there will be cohesion in the home. The dearth of empirical evidence on the predictive powers of parental social support and domestic violence on child abuse among primary school pupils in Nigeria necessitated this research.

\subsection{Research Questions}

The following research questions were posed for the study:

1) What is the predictive power of parents' social support on child abuse?

2) What is the predictive power of parents' domestic violence on child abuse? 


\subsection{Hypotheses}

The following hypotheses were formulated to guide the study and were tested at a 0.05 level of significance.

$\mathbf{H o}_{1}$ : Parents' social support has no significant predictive power on child abuse among pupils.

$\mathrm{Ho}_{2}$ : Parents' domestic violence has no significant predictive power on child abuse among pupils.

\section{Materials and Methods}

This study adopted a correlational survey research design. Correlational survey research design seeks to establish the relationship that exists between two or more variables (Nworgu, 2015). The study was carried out with primary 5 pupils in the South-East, Nigeria which is made up of five states, namely, Abia, Anambra, Ebonyi, Enugu and Imo States. The people of South-East, Nigeria are educationally-minded as there are various educational institutions established all around the states. The presence of these institutions is expected to encourage and motivate the people of the states to be involved and participate actively in school and education programmes, leading to parental high education qualifications, hence good occupations that enhance parental social support, discouraging parental domestic violence, child abuse and result in high academic achievement of pupils. More still, since the people of this area are presumed to be highly educated, civilized and cultured it is shocking to notice seeming indelibility of child abuse.

The population of the study comprised 418,533 primary five (5) pupils in all the 5,453 public primary schools in South-East, Nigeria. The sample size of the study was 400 primary five pupils. The multi-stage sampling procedure was used to arrive at the sample size. At the first stage, simple random sampling by balloting with replacement was used to draw 3 states; Anambra, Ebonyi and Enugu states out of the 5 states of South-East, Nigeria. Secondly, proportionate stratified random sampling was used to sample 20 Local Government Areas (L.G.A) from the states sampled. Proportionate Stratified Sampling was used because the states do not have an equal number of L.G.As. At the third stage, Simple Random Sampling technique by balloting with replacement was used to select two primary schools from each of the 20 L.G.As sampled. Finally, simple random sampling by balloting with replacement was used to draw 10 primary 5 pupils from each of the 40 primary schools sampled making 400 pupils.

Three instruments were used for data collection of this study. They are the pupils' Parental Social Support Questionnaire (PSSQ), Parental Domestic Violence Questionnaire (PDVQ), and Child Abuse Questionnaire (CAQ). The Parental Social Support Questionnaire (PSSQ) contains two sections, A and B. Section A contained information on the personal data of the respondents, while section B contained 10 items on parental social support. The Parental Domestic Violence Questionnaire (PDVQ) is made up of two sections, A and B. Section A contained information on the personal data of the respondent and the respondent's parents while section B contained 10 items on parental domestic violence. The Child Abuse Questionnaire (CAQ) contained two sections as well. Section A contained the demographic information of the respondent and the respondent's parents. Whereas section $\mathrm{B}$ has 20 items on child abuse and contained four clusters, A, B, C, D. Cluster A contained 4 items on physical abuse, cluster B contained 4 items on sexual abuse, and cluster $C$ contained 4 items on emotional/psychological abuse while cluster D contained 4 items on child neglect. The instruments were structured on a four-point rating scale of Very Great Extent (VGE) - 4points; Great Extent (GE) - 3points; Little Extent (LE) -2points and Very Little Extent (VLE) -1 point. The respondents were requested to indicate the level of agreement on each item by ticking $(\sqrt{ })$.

The instruments were face validated by three experts: one in Childhood Education Unit, one in Educational Psychology and one in measurement and evaluation, all in the Faculty of Education, University of Nigeria, Nsukka (UNN). The experts were requested to go through the instruments and ascertain their appropriateness for the study bearing in mind the purposes of the study, research questions, and hypotheses. The experts were also requested to check the appropriateness of the language and the instructions given to the respondents. Three copies of the validated instruments were retrieved from the experts. Thus, based on their comments and suggestions, corrections were made to improve the quality of the instruments.

The instruments were trial tested on a sample of 30 primary school pupils who were randomly drawn from Holiness Nursery and Primary School, Otukpo, Benue State, which is outside the area of the study but has the same characteristics with the area of the study. The data obtained were subjected to reliability estimate in order to determine the internal consistency reliability indices of the items of the instruments using Cronbach's Alpha method since the items were polychromous scored. The reliability coefficients of 0.88 and 0.80 were obtained for Parental Social Support Questionnaire and Parental Domestic Violence Questionnaire respectively. For the various clusters of Child abuse questionnaire, reliability indices of $0.89,0.79,0.87$ and 0.79 were obtained for Physical Child Abuse, Sexual Child Abuse, Emotional/Psychological Child Abuse and Child Neglect, while the overall reliability index of 0.75 was obtained for Child Abuse Questionnaire. 
Data collected were analyzed using simple linear regression analysis. Specifically, Correlation Coefficient and Coefficient of Determination $\left(\mathrm{r}^{2}\right)$ were used to answer research questions and Analysis of Variance (ANOVA) aspect of simple linear regression was used to test the null hypotheses at 0.05 level of significance. In taking decision on the research questions, a correlation coefficient within the range of 0.1 to 0.39 indicated low predictive power, that within 0.40 to 0.69 indicated moderate predictive power while that within 0.7 to 1.0 indicated high predictive power.

\section{Results}

\subsection{Research Question One: What is the Predictive Power of Parents'Social Support on child Abuse?}

Table 1. Regression analysis of the predictive power of parents' social support on child abuse

\begin{tabular}{lllll}
\hline Model & $\mathrm{R}$ & R Square & Adjusted R Square & Std. Error of the Estimate \\
\hline 1 & $-.540^{\mathrm{a}}$ & .292 & .290 & 14.94049 \\
\hline
\end{tabular}

a. Predictors: (Constant), Parents, Social Support.

Table 1 reveals that the correlation coefficient between parents' social support and child abuse is -0.540 with a coefficient of determination of 0.292 . This shows that there is a negative relationship between parents' social support and child abuse. Thus, the more the parents' social support, the less the child abuse. Besides, a coefficient of determination of 0.292 means that 29.2 per cent of the negative variation in pupils' child abuse can be attributed to parents' social support. In other words, the predictive power of parents' social support on pupils' child abuse is 29.2 per cent.

$\mathbf{H o}_{1}$ : Parents' social support has no significant predictive power on child abuse among pupils.

Table 2. Analysis of variance of the predictive power of parents' social support on child abuse

\begin{tabular}{lllllll}
\hline Model & & Sum of Squares & df & Mean Square & F & Sig. \\
\hline \multirow{2}{*}{1} & Regression & 36567.778 & 1 & 36567.778 & 163.821 & $.000^{\mathrm{b}}$ \\
& Residual & 88840.919 & 398 & 223.218 & & \\
& Total & 125408.697 & 399 & & & \\
\end{tabular}

a. Dependent Variable: Child Abuse.

b. Predictors: (Constant), Parents' Social Support.

Table 2 shows that parents' social support had a significant predictive power on child abuse among pupils, $F(1,398)$ $=163.821, p=0.000$. This is for the fact that the associated probability value of 0.000 is less than the 0.05 level of significance. Thus, the null hypothesis of no significant predictive power was rejected. Therefore, 29.2 per cent negative variation in pupils' child abuse can be attributed to parents' social support while the remaining 70.8 percentage can be attributed to other factors other than parents' social support.

\subsection{Research Question Two: What Is the Predictive Power of Parents'Domestic Violence on Child Abuse?}

Table 3. Regression analysis of the predictive power of parents' domestic violence on child abuse

\begin{tabular}{lllll}
\hline Model & $\mathrm{R}$ & R Square & Adjusted R Square & Std. Error of the Estimate \\
\hline 1 & $.712^{\mathrm{a}}$ & .506 & .505 & 12.47232 \\
\hline
\end{tabular}

a. Predictors: (Constant), Parents' Domestic Violence.

Table 3 reveals that the correlation coefficient between parents' domestic violence and child abuse is 0.712 with a coefficient of determination of 0.506 . This shows that there is a positive relationship between parents' domestic violence and child abuse. Thus, the more the parents' domestic violence, the more the child abuse. Besides, a coefficient of determination of 0.506 means that 50.6 per cent positive variation in pupils' child abuse can be 
attributed to parents' domestic violence. In other words, the predictive power of parents' domestic violence on child abuse is 50.6 per cent.

$\mathbf{H o}_{2}$ : Parents' domestic violence has no significant predictive power on child abuse among pupils.

Table 4. Analysis of variance of the predictive power of parents' domestic violenceon child abuse

\begin{tabular}{lllllll}
\hline Model & & Sum of Squares & df & Mean Square & F & Sig. \\
\hline \multirow{2}{*}{1} & Regression & 63496.323 & 1 & 63496.323 & 408.182 & $.000^{\mathrm{b}}$ \\
& Residual & 61912.375 & 398 & 155.559 & & \\
& Total & 125408.697 & 399 & & & \\
\hline
\end{tabular}

a. Dependent Variable: Child Abuse.

b. Predictors: (Constant), Parents' Domestic Violence.

Table 4 shows that parents' domestic violence had a significant predictive power on child abuse among pupils, $F(1$, $398)=408.182, p=0.000$. For the fact that the associated probability value of 0.000 is less than the 0.05 level of significance, the null hypothesis was rejected. Therefore, 50.46 per cent positive variation in pupils' child abuse can be attributed to parents' domestic violence. Thus, the remaining 49.54 percentage can be attributed to other factors other than parents' domestic violence.

\section{Discussion of the Findings}

The findings of the study revealed that there is a negative relationship between parents' social support and child abuse. Further analysis showed that parents' social support had a significant predictive power on child abuse among pupils. Thus, the more the parents' social support, the less the child abuse. The findings are in line with the findings of Jonzon (2006) who found out that adequate social support to mothers is a cushion against child abuse and Tusiime (2014) who discovered that parents' support received by the pupils acts as a shield against child abuse. The finding of the study also corroborated the finding of Mayo and Sumihisa (2017) who in related study revealed that mothers with a low-level scale of social support had higher child abuse potentials than those with the high-level scale of perceived social support. This could be because of the care, love and social interaction that in engendered by social support. The findings imply that the more social support parents offer the child the less abusive such parents could be. This is to say that pupils who receive high level of parents' social supports are less abused when compared to their counterparts who receive less support.

The findings of the study also showed that there is a positive relationship between parents' domestic violence and child abuse. It was further found that parents' domestic violence had a significant predictive power on child abuse among pupils. The findings of this study are in line with Horner (2005) who pointed out that children who witness domestic violence live in constant fear and are 15 times more likely to be victims of child abuse than other children. The finding also validated the position ofEdleson, Ellerton, Seagren, Eirchberg and Ambrose (2007) who stated that children who are exposed to IPV are most likely to exhibit traits of abuse and violence in school since they have been abused themselves. The finding of the study is that children who witness domestic violence are invariably abused. This could be because hatred and anger are intricate aspects of domestic violence. This means that domestic violence is child abuse in itself and a parent who involves in domestic violence is an abuser. Thus, the more there is parents' domestic violence, the more the child abuse.

\section{Conclusion and Recommendations}

Parental social support is a negative determinant of child abuse among pupils, while parents' domestic violence is a positive determinant of child abuse among pupils. This implies that teachers and caregivers would be better placed to counsel parents on the need to offer the children enough social support and avoid exposing the children to parental domestic violence. It was therefore recommended that;

1) Parents should provide enough social support to the children so as to avoid child abuse and enhance academic achievements in social studies.

2) Parents should desist from all forms of domestic violence among themselves especially in the presence of the children so as to avoid emotional child abuse. 


\section{Acknowledgements}

The researchers acknowledged all the participants used for the conduct of this research. Primary school pupils and their teachers are highly acknowledged for their esteemed cooperation during the conduct of the research.

\section{Competing Interests Statement}

The authors declare that there are no competing or potential conflicts of interest.

\section{References}

Ajila, C., \& Olutola, A. (2001).The effects of family structure and parenthood on the academic performance of Nigerian University Students. InV.O. Uwaifo, (n.d.).

Bedford Borough Council. (2018). Who is a parent? Retrieved from https://www.bedford.gov.uk/education_and_learning/education_welfare_service/school_attendance_and_th e_law/who_is_a_parent.aspx

DeHoff, B. A., Staten, L. K., Rodgers, R. C., \& Denne, S. C. (2016). The role of online social support in supporting and educating parents of young children with special health care needs in the United States: a scoping review. Journal of medical Internet research, 18(12), e333. Retrieved from https//www.ncbi.nlm.nih.gov/pmc/pmc5216258/

Browne, C. L. (2012). Papa's Baby: Paternity and Artificial Insemination. Retrieved from https://en.wikipedia.org/wiki/Parent.

ChinginMinds.org. (2018). The needs of children. Retrieved from http://changingminds.org/ explanations/needs/children_needs.htm

Edleson, J. L., Ellerton, A. L., Seagren, A. E., Kirchberg, S. O., \& Ambrose, A. T. (2007). Assessing child exposure to adult domestic violence. Children and Youth Services Review, 29(7), 961-971. https://doi.org/10.1016/j.childyouth.2006.12.009

Fairbrother, N. (2011). Social support. Visions, 6(4), 7-10. Retrieved from https://www.verywellmind.com/social-support-for-psychological-health-4119970

Florida Coalition against Domestic Violence (FCADV). (2014). 3rd Annual event. Retrieved from https//www.fcadv.org

Gottlieb, B. H., \& Bergen, A. E. (2010).Social support concepts and measures. Journal of psychosomatic research, 69(5), 511-520. Retrieved from https://www.sciencedirect.com/science/article/pii/S0022399909004115

Heredia, N. I., Ranjit, N., Warren, J. L., \& Evans, A. E. (2016). Association of parental social support with energy balance-related behaviors in low-income and ethnically diverse children: A cross-sectional study. BMC public health, 16(1), 1182. https://doi.org/10.1186/s12889-016-3829-8

Horner, G. (2005). Domestic violence and children: the effects of domestic violence on children. Journal of Pediatric Health Care, 19(4), 206-212.https://doi.org/10.1016/j.pedhc.2005.02.002

Johanna, C. (2015). The Basic Needs of children. Retrieved from http://www.healthguidance.org/entry/14969/1/the-basic-needs-of-every-child.html

Jonzon, E. (2006). Child sexual abuse: Disclosure, social support and subjective health in adulthood. Institutionen för folkhälsovetenskap/Department of Public Health Sciences. Retrieved from https://openarchive.ki.se/xmlui/handle/10616/38843

Nwana, O. C. (1990). Introduction to educational research. Ibadan: Heinemann Education Books Ltd.

Obekpe, I. A. (2011). Child abuse: Consequences and effects on education and society. International Journal of Continuing Education, 2(2), 136-147.

Ruholt, R., Gore, J. S., \& Dukes, K. (2015). Is parental support or parental involvement more important for adolescents? Undergraduate Journal of Psychology UNC Charlotte, 28(1), 1-8.

Sue, D. W. (2015). Therapeutic harm and cultural oppression. The Counseling Psychologist, 43(3), 359-369. https://doi.org/10.1177/0011000014565713

Mayo, O., \& Sumihisa, H. (2017). Association between social support and child abuse potential among Japanese mothers. Journal of Children and Youth Services Review, 73, 88-92. https://doi.org/10.1016/j.childyouth.2016.12.003 
Tusiim, C. (2014). Child abuse, perceived social support, self-esteem and academic performance among primary school children in Kabale district. Retrieved from http://www.makir .mak.ac.ug/handle/10570/4384

\section{Copyrights}

Copyright for this article is retained by the author(s), with first publication rights granted to the journal.

This is an open-access article distributed under the terms and conditions of the Creative Commons Attribution license (http://creativecommons.org/licenses/by/4.0/). 